\title{
As estratégias de administração das políticas públicas de educação na cidade do Rio de Janeiro entre 1922 e 1935
}

\section{André Luiz Paulilo}

Universidade Municipal de São Caetano do Sul
Uma preocupação com a administração e o desenvolvimento da educação popular é particularmente visível nos anos de 1920 e 1930. Na capital da República, Carneiro Leão (entre 1922 e 1926), Fernando de Azevedo (de 1927 a 1930) e Anísio Teixeira (a partir de 1931 até 1935) ocuparam a direção da instrução pública, o posto-chave da administração escolar na cidade. Durante essa quase década e meia, tanto produziram intensa documentação administrativa e legislação quanto trataram da organização administrativa do ensino em livros e publicações diversas. $\mathrm{O}$ período foi, sobretudo, de importante reorganização do funcionamento escolar na cidade do Rio de Janeiro. Iniciativas como ampliação do número de turnos escolares, a reestruturação da carreira do magistério, a implantação de novos serviços educativos e a utilização da estatística permitiram redimensionar a capacidade de atendimento da instrução pública na capital à época. Embora invariavelmente comprometido com referências ao "cipoal de leis” e à "excessiva burocratização dos serviços de ensino”, o tema da administração escolar possibilita principalmente abordar o processo de decisão que essas ações envolveram.
Este artigo é uma tentativa de entender os aspectos centrais da política e da administração do ensino na capital do Brasil entre 1922 e 1935. Há preocupação com o órgão que mais diretamente viabilizou a política educativa de Carneiro Leão, Fernando de Azevedo e Anísio Teixeira: a Diretoria Geral de Instrução Pública. Leva-se em conta o modo de reorganizar o mando nas instâncias administrativas dos serviços educativos à luz de alguns dilemas políticos da gestão do poder no período. Nesse sentido, a análise põe em foco a instituição central da administração do ensino na cidade do Rio de Janeiro como forma de discutir suas atribuições. Em que pesem os nexos entre os diversos órgãos de decisão político-administrativa do Distrito Federal, o foco na Diretoria de Instrução visa mostrar as margens de manobra que era possível ter no comando da educação pública. Dessa perspectiva, a ênfase da abordagem recai sobre as estratégias do mando e o modo como se constituíram institucionalmente e, ao mesmo tempo, foram se tecendo ao sabor de conjunturas e de atuações individuais. Em outras palavras, o esforço da análise se dá no sentido de mostrar o 
papel operatório da administração escolar na implementação de um novo projeto educacional.

No trato com o órgão central da administração escolar, fundamentalmente se pergunta sobre a ação dos principais administradores. Perguntar sobre o que fizeram Carneiro Leão, Fernando de Azevedo e Anísio Teixeira para administrar a educação pública da capital do país foi a forma encontrada para pensar algumas das estratégias de reforma do ensino. Na hipótese de que as reformas do ensino público da capital entre 1922 e 1935 tenham traduzido decisões políticas em ações institucionais é central na abordagem deste texto explicitar algo dos processos por meio dos quais isso ocorreu. Assim, a proposta analítica que se segue intenta realçar a dimensão inovadora e engenhosa das manobras organizadoras levadas a cabo nas principais instituições da administração do sistema escolar do período. No rastro da história da racionalização utilitária do detalhe que busquei aplicar no doutoramento, este estudo procede da preocupação com o modo de as reformas educativas fazerem funcionar as muitas tecnologias de uma racionalidade própria à aprendizagem escolar.

\section{Uma política de reforma da instrução pública}

Entre a posse de Carneiro Leão na Diretoria de Instrução Pública em 1922 e a exoneração de Anísio Teixeira da Secretaria de Educação e Cultura em 1935, a administração do ensino público no Distrito Federal foi inteiramente reformada. Até 1927 com um gabinete de despachos e uma secretaria de expedientes funcionais, o órgão central da administração do ensino na capital do país chegou a reunir, quase uma década depois, dois institutos, seis divisões de serviço e sete superintendências.

Em 1928, o decreto n. 3.281, de 23 de janeiro, criou a Subdiretoria Técnica para a Diretoria Geral de Instrução Pública do Distrito Federal, reunindo todo o trabalho de secretaria numa outra subdiretoria, a Administrativa. Como determinava a regulamentação da nova lei de ensino, eram competência da Subdiretoria Técnica os serviços de propaganda e publicidade da educação popular e o desenvolvimento de medidas para ampliar tanto as instituições de assistência e cooperação da escola e da família quanto as instituições de aperfeiçoamento do ensino, como cinema educativo, museus escolares e bibliotecas. Composta por uma seção de expediente, outra de contabilidade e as seções de arquivo e estatística, a Subdiretoria Administrativa mantinha organizada a burocracia e a logística dos serviços educativos. Dessa forma, a reforma do ensino em 1928 estabeleceu uma primeira separação dos setores administrativos e técnicos na Diretoria Geral de Instrução Pública do Distrito Federal. Por um lado, então, a Subdiretoria Administrativa encarregava-se da estruturação dos aspectos administrativo-burocráticos que definiam a implementação das novas medidas adotadas. Por outro, o estudo e a solução de problemas de ordem técnico-pedagógica eram atribuições da Subdiretoria Técnica. O período entre 1928 e 1932 na educação da capital pode ser visto como de enquadramento das relações que se estabeleceram entre o pessoal encarregado das tarefas educativas e de secretariado na estrutura administrativa.

Um pouco depois de assumir a direção do ensino na cidade do Rio de Janeiro em 1931, Anísio Teixeira iniciou um decisivo processo de ampliação da organização administrativa do ensino. O decreto n. 3.763, de $1^{\circ}$ de fevereiro de 1932, reconstituiu a Diretoria Geral de Instrução Pública, criando os serviços de matrícula escolar, promoção de alunos, programas, educação física, música e canto orfeônico, ensino secundário geral e profissional, prédios e aparelhamentos escolares e rearticulando outros (contabilidade, pessoal e arquivo, expediente e publicidade, estatística e cadastro, obras sociais e escolares e educação de saúde e higiene escolar).

Mas foi no ano seguinte, com a transformação da Diretoria de Instrução em Departamento de Educação, que Anísio Teixeira consolidou uma nova estrutura técnico-administrativa para o ensino público na capital federal. O decreto n. 4.387, de 8 de setembro de 1933, constituiu o Departamento de Educação a partir da organização de institutos e divisões técnicas e administrativas, de estudo e coordenação, e de órgãos de administração, orientação e fiscalização. $O$ conjunto 
compreendia o Instituto de Educação; o Instituto de Pesquisas Educacionais, com duas divisões: a de Pesquisas Educacionais e a de Obrigatoriedade Escolar e Estatística; a divisão de Bibliotecas Escolares e Cinema Educativo; a divisão de Prédios e Aparelhamentos Escolares, a Divisão de Secretaria; as Superintendências especializadas de Música e Arte, Desenho e Artes Industriais e Educação Física, Recreação e Jogos; a Superintendência Geral de Educação de Saúde e Higiene Escolar; a Superintendência de Educação Secundária Geral e Técnica e do Ensino de Extensão; as Superintendências de Educação Elementar e as Superintendências de Ensino Particular.

Em 1935, a lei n. 17, de 2 de setembro, transformou o Departamento de Educação da Prefeitura do Distrito Federal em Secretaria de Educação e Cultura, com poucas alterações. A estrutura então constituída por Anísio Teixeira funcionava por meio de serviços de estudo, coordenação, controle e atuação direta e indireta sobre a escola. Conforme a compreensão do diretor do departamento de educação, tratava-se de dar à administração educacional a fisionomia técnica e especializada igual à de Saúde Pública e a de serviços ligados à engenharia (Teixeira, 1935, p. 63). O princípio com o qual Anísio se justificou e que consagrou na reorganização do Departamento de Educação foi o da distinção entre as ações executivas e as de assistência técnica. Sobreleva a nitidez da distinção que então se fez entre os órgãos de execução e provimento das condições de realização das ações de reforma e as repartições encarregadas de assistir e auxiliar a execução. O próprio Anísio Teixeira (1935, p. 65) reconheceu o caráter consultivo e técnico dos Institutos de Educação e de Pesquisas Educacionais e das Divisões de Obrigatoriedade Escolar e Estatística e de Prédios e Aparelhamentos Escolares, deixando reservadas às superintendências as funções de execução e desenvolvimento do trabalho escolar. Continuamente interessado em instituir um efetivo sistema público de ensino, Anísio estabeleceu e definiu as atribuições de toda uma rede de controle dos serviços educativos da cidade. Nunes (2000, p. 238) tem razão quando diz que esse projeto nunca escondeu sua consciência raciona- lizadora. Para Anísio Teixeira (1935, p. 63), a reforma da administração central da educação pública se fazia em nome de "um reconhecimento otimista de que o problema da organização e da articulação eficazes de um sistema escolar pode vir a ser resolvido”.

Embora a concepção de que a reforma administrativa da educação pública era uma estratégia para solucionar os problemas de extensão e qualidade da escola elementar tenha surtido resultados muito concretos entre 1928 e 1935, a figura central para a compreensão dos propósitos gerenciais às vistas das reformas do ensino foi anterior a esse período. No quadriênio de 1922 a 1926, Carneiro Leão consolidou uma visão política do gerenciamento da educação pública que permaneceu influente até 1935 no Distrito Federal. Fundamentalmente, tratou-se de um momento pouco reconhecido pelas realizações de reforma ou pelas iniciativas de organização escolar, mas continuamente referido como fecundo de ideias inteligentes e lúcidas de renovação do sistema público de ensino (Zentgraf, 1994). Tanto se encontram nele as pretensões de Azevedo e Anísio a respeito do desvencilhamento entre atribuições técnicas e tarefas administrativo-burocráticas na direção do ensino quanto as preocupações em relação à articulação dos serviços escolares e sistematização da educação popular. Em seu livro sobre a reforma do ensino que conduziu no Rio de Janeiro, Carneiro Leão (1926, p. 7) tratou a direção do ensino como tarefa de caráter social e político. Sua ênfase na ideia de que a solução dos problemas de natureza cívica e nacional dependia de aparelhar a escola pública para uma obra de nacionalização dos costumes pode ser notada em boa parte das iniciativas de reforma. Foi principalmente assim que Carneiro Leão (1926, p. 52, p. 130-137, p. 214) justificou as necessidades de uma maior dotação orçamentária para a educação, incentivou solenidades escolares de caráter cívico ou social e frisou o papel da escola na orientação vocacional da criança. Por outro lado, as medidas de amparo material e assistência médica e alimentar mostraramse relevantes no balanço efetuado pelo diretor da instrução carioca em 1926. Para Carneiro Leão, as ações de defesa da saúde nas escolas, a organização da 
assistência escolar e a criação e generalização da educação física pareceram ser importantes indicativos do alcance social das iniciativas que fez organizar quando na Diretoria Geral de Instrução Pública do Distrito Federal. Significativamente, os principais benefícios para a criança contabilizados no relato do diretor da instrução advêm de empreendimentos vinculados aos serviços de inspeção médica e de distribuição da merenda escolar: alimentação, vacinação, exame de saúde e tratamento dentário.

Ambos os conjuntos de medidas coincidiram no esforço de aumentar os anos de escolaridade da população em geral e das classes operárias em especial. Carneiro Leão (1926, p. 8) argumentou que o acréscimo do tempo de escolarização das crianças era condição necessária para "preparar o nosso povo para assimilar os estrangeiros que nos procuram”. E, de fato, organizou o programa de ensino das escolas primárias diurnas em sete anos, um acréscimo de dois anos em relação ao período de educação elementar vigente desde 1919. O diretor de instrução da capital justificou tal providência esclarecendo a importância de um estágio escolar elevado:

\footnotetext{
Pouco há de valer um ensino de dois ou três anos dado aos cidadãos de uma capital, como o Rio de Janeiro, se para aqui imigram milhares e milhares de filhos de povos em que a cultura popular mínima corresponde a 7, 8 e 9 anos de estudo e com um trabalho escolar de 30 horas por semana, quando nós temos 22 horas de tal trabalho nas escolas de dois turnos e 25 nas de turno único. (Carneiro Leão, 1926, p. 8)
}

Do mesmo modo, as iniciativas de assistência escolar, social, alimentar e de saúde compunham uma estratégia de ampliação do tempo médio de escolarização da população. Carneiro Leão (1926, p. 14) compreendeu sobretudo que atrair e manter por mais tempo as crianças na escola também era uma tarefa administrativa de ordem social:

A preocupação diante da escassez da matrícula nos últimos anos não podia ser a redução do estágio, mas a atração da população infantil às classes superiores. Daí a atenção da
Diretoria para o problema da assistência, estimulando a criação e o desenvolvimento das Caixas Escolares, Ligas de Bondade, Copos de Leite, Sopas Escolares, Gabinetes Dentários, para que o esforço particular viesse em auxílio do poder público e pudessem os deserdados da sorte conseguir uma preparação para a vida capaz de evitar a sua condenação aos trabalhos braçais, sem beleza e sem futuro. Por toda parte em que tais medidas se generalizam, a matrícula cresce, a frequência se eleva consideravelmente.

Tanto no sentido de ampliar os anos de estágio escolar gratuito quanto no de atrair e manter as crianças por mais tempo na escola, a Diretoria Geral de Instrução providenciou soluções de extensão dos serviços escolares, quer em tempo, quer em recursos. Esse propósito era muito nítido em 1924, quando Carneiro Leão apresentou um anteprojeto de reforma da instrução pública para o então prefeito do Distrito Federal, Alaor Prata.

A Justificação do Plano de Reforma apresenta não só uma concepção clara de sistema público de ensino como os meios de sua subvenção e controle. Para Carneiro Leão (1926, p. 219), começando no jardim da infância ou na escola primária, a criança deveria atravessar o curso fundamental e passaria daí para uma escola profissional ou seguiria, em linha direta, pelo curso complementar até a Escola Normal, se não se encaminhasse antes para os cursos secundários e a universidade. Nesse esquema, foi central o esforço de conduzir o aluno do curso fundamental para a escola profissional como forma de iniciá-lo na aprendizagem de um ofício e prolongar sua escolarização. Significativamente, respeitou-se o limite máximo que os rapazes pobres atingiam na escola primária, entre o $3^{\circ}$ e $4^{\circ}$ anos, flexibilizando-se os critérios de admissão aos cursos técnico-profissional. Contudo, essa proposta para fazer da instrução um bloco ajustado e completo de escolarização se consolidava através de dispositivos de assistência e inspeção. Em parte, as estratégias para prolongar os efeitos dos serviços escolares sobre a população infantil pobre foram pensadas a partir da oferta de merenda, tratamento dentário, assistência de saúde e pensões e merenda (Carneiro Leão, 1926, p. 227-228, p. 231-232). Em contrapartida, a justifica- 
tiva de reforma admitia que as modificações do ensino público dependiam apenas de uma organização administrativa "mais harmônica e mais consentânea com a importância dos estabelecimentos e a sua finalidade no meio" (Carneiro Leão, 1926, p. 233). Embora se achasse que, fora isso, a questão era de programas, nos quais o ensino das matérias se faria mais experimental e de acordo com os cursos da Escola Normal e das escolas profissionais, os cursos de formação docente em serviço e a remodelação dos serviços de secretaria mostravam a compreensão que então havia da reforma educativa como um problema de ajustamento das inovações ao aparelhamento escolar.

O projeto sequer foi encaminhado para a apreciação no Conselho Municipal. No entanto, suas bases permaneceram visíveis nos procedimentos da Diretoria Geral de Instrução Pública. Ao relatar o esforço empreendido no quadriênio em que administrou o ensino da capital, Carneiro Leão (1926, p. 46-49) examinou o que se procurou conseguir dentro de um plano de finalidades:

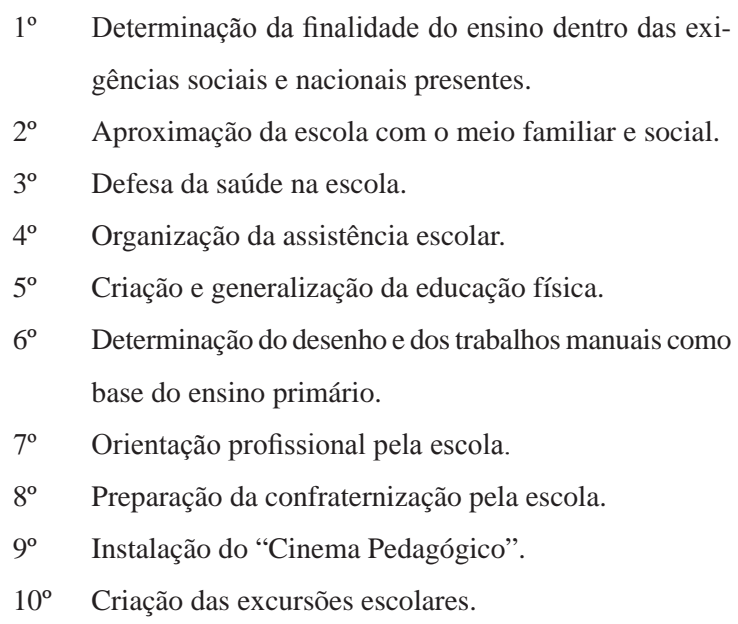

Carneiro Leão (1926, p. 49) elaborou um relato dos trabalhos realizados na Diretoria de Instrução em que ficou acentuada a preocupação de seguir uma finalidade conscientemente determinada. Nos termos do seu relato, a finalidade do ensino foi definida nos cursos de formação dos professores e estabelecida na reforma dos programas primário, normal, noturno e profissional. Sem conseguir modificar a lei de regu- lamentação do ensino público, Carneiro Leão (1926, p. 49) agiu por meio de medidas administrativas orientadas em função do que entendia serem as "nossas características sociais e nacionais”.

Ainda de acordo com o relato de Carneiro Leão (1926, p. 199), a implementação desse plano de finalidades ressentiu-se do modelo organizacional da Diretoria Geral de Instrução Pública, que era repleta "de empecilhos regulamentares no movimento de papéis”. Sobretudo a crítica registrada pelo diretor da instrução pública visou o acúmulo das funções técnicas e burocráticas do cargo. A falta de uma subdiretoria técnica não só causava sobrecarga de trabalho burocrático, segundo Antônio Carneiro Leão (1926, p. 199), como impedia "uma distribuição de serviço mais racional”. Consequentemente, pleiteava-se a criação das subdiretorias técnica e administrativa para desafogar os afazeres do diretor de instrução (Carneiro Leão, 1926, p. 200). Essa sugestão de solução tinha no seu cerne a concepção de que as funções técnicas da direção do ensino precisavam estar desvencilhadas da sua parte burocrática para terem maior eficiência. Basicamente, o relato de Carneiro Leão sobre os resultados dos seus trabalhos no quadriênio de 1922 a 1926 suscitou a expectativa de uma organização da Diretoria Geral de Instrução semelhante à que já funcionava em outras repartições da Prefeitura do Distrito Federal.

Embora sem autorização para a reforma da Diretoria Geral, Carneiro Leão redimensionou o alcance dos seus serviços. Por meio das comissões de trabalho e pesquisa e a incorporação de ações de assistência aos dispositivos de controle sanitário das escolas, assegurou-se a organização das práticas de prevenção, de assistência escolar e promoção da saúde e a experimentação de novas fórmulas de ensino e avaliação. Para implementar alguma mudança na rotina de trabalho das escolas da capital, Carneiro Leão tanto constituiu grupos de atividades quanto aproveitou grupos já mobilizados para assistir aos necessitados. Fundamentalmente, agiu por meio da rede de comissões e do agenciamento de inspetores, professores e funcionários que pôde organizar em 
torno da administração do ensino e da escola. Em vez de uma reforma das instituições do serviço educativo, Carneiro Leão recondicionou as relações sociais e de trabalho no seu interior. Mesmo impedido de realizar qualquer remodelação institucional, o diretor da instrução pública do Distrito Federal alterou a abrangência da ação administrativa da Diretoria Geral. Sobrepôs ao modelo de organização da Diretoria Geral procedimentos auxiliares de assistência escolar e de estudo e pesquisa que, se por um lado não alteraram a estrutura de funcionamento desse órgão, por outro serviram para desenvolver atividades formativas e de proteção social segundo princípios claramente definidos.

\section{Transformações no modelo organizacional da Diretoria de Instrução do Distrito Federal}

Os propósitos de Carneiro Leão quanto ao plano de finalidades sociais que a escola deveria satisfazer não apenas permaneceram sendo uma política de atuação da Diretoria de Instrução no período seguinte como, em parte, foram viabilizados. Com a criação da Subdiretoria Técnica em 1928, Fernando de Azevedo institucionaliza o órgão que Carneiro Leão reivindicava em 1926 para constituir a unidade de pensamento e a ação construtora das reformas educativas. E, de fato, foi por intermédio da Subdiretoria Técnica que a administração do ensino na capital organizou o curso de conferências “A Escola Nova e a Reforma”, entre abril e maio de 1928, a Exposição de Cinema Educativo, em 1929, o Curso de Educação Sanitária, em 1929, e a edição do Boletim de Educação Pública, periódico oficial da Diretoria Geral lançado em 1930. Igualmente da alçada da Subdiretoria Técnica a realização dos concursos públicos para provimento dos cargos docentes da Escola Normal e os processos de licitação para a construção de novos edifícios escolares. Como observou Jorge Nagle (1974, p. 202-203), as atribuições de natureza técnico-pedagógica das seções técnicas das diretorias de instrução nos anos de 1920 resultaram de um esforço geral no sentido de aperfeiçoar e tornar eficiente o funcionamento da rede escolar. Como Nunes (2000) em relação aos anos 1930, também Nagle (1974, p. 205) falou em racionalização para descrever as atribuições de direção voltadas ao estudo e solução dos problemas técnicos. Principalmente, ele reconheceu que no campo da administração escolar a decisão de criar a Subdiretoria Técnica permitiu a formulação de algumas estratégias para a ação imediata sobre a escola: a transformação da inspeção escolar, de serviço fiscalizador em instrumento de assistência técnica; o estabelecimento de concursos para o preenchimento de cargos, a estruturação da carreira do magistério e a realização de recenseamentos escolares (Nagle, 1974, p. 204).

Outro conjunto de estratégias que se consolidou na Diretoria Geral de Instrução Pública entre 1922 e 1930 tem a ver com a política de pessoal. As comissões para Estudo e Aplicação dos Testes, para Generalização da Educação Física, para reelaboração dos Programas Escolares e para Compilação das Leis de Ensino, em atividade a partir de 1924, compunham-se de professores, especialistas e inspetores indicados por Carneiro Leão para estudo, implantação ou planejamento de ações relacionadas a objetivos específicos de reforma. Em relação à estrutura de cargos da Diretoria Geral de Instrução, elas apenas referenciavam uma função técnica ou administrativa, tornando mais evidentes algumas das propostas de direção. Entretanto, o foco especializado das comissões dava relevância profissional aos seus componentes por meio de publicações ou cursos de formação. No trabalho comissionado, a administração não só se aproveitava da autoridade técnica de alguns professores do quadro de funcionários da Diretoria Geral, da Escola Normal ou das próprias escolas como também conferia visibilidade ao trabalho desenvolvido. Essa solução de organização de alguns serviços reuniu, em torno de alguns pontos do plano de finalidades administrativas, docentes e inspetores escolares competentes para capacitar nas novas tarefas propostas, destacando-os e legitimandoos como autoridades técnicas. Entre muitos outros, os professores da Escola Normal Manoel Bomfim, Maurício de Medeiros, Nereu Sampaio, Edgard Sussekind de Mendonça e José Paranhos Fontenelle, os inspetores escolares Paulo Maranhão e Deodato de Morais, o diretor da Escola Profissional Visconde 
de Cayru, Theophilo Moreira, o catedrático Joaquim Ferreira de Souza, o adjunto Jayme Pereira Batista e a adjunta Nicolard Frossard integraram comissões de trabalho tanto assumindo responsabilidades a respeito da pesquisa e experimentação quanto participando das iniciativas de formação da Diretoria Geral. Embora limitado, o recurso aos trabalhos comissionados foi uma possibilidade de Carneiro Leão operar prescindindo de uma lei de reforma da instrução. Em que pesem as restrições da base organizacional da administração central do ensino, esse tipo de manobra revelou-se de relevância para indicar diretrizes novas de trabalho.

A partir de 1928, a aprovação e regulamentação da reforma do ensino permitiram a Fernando de Azevedo repensar a composição dos cargos da Diretoria Geral de Instrução Pública. A criação das Subdiretorias Técnica e Administrativa e da função de inspetor médicoescolar chefe constituíram postos-chave de comando na gestão do ensino público na capital. Em parte, a reestruturação burocrático-administrativa do mando na educação serviu para estabelecer atribuições de serviço superintendidas e orientadas por uma autoridade de competência especializada. Tanto a Subdiretoria Administrativa quanto a Técnica e a chefia dos serviços médico-escolares deixavam entrever a ideia de tornar eficientes os serviços educativos por meio da especialização das ações supervisoras. Nesse sentido, os recursos que Nagle (1974, p. 204) identificou quando descreveu as medidas para proporcionar maior eficiência ao funcionamento dos sistemas escolares nos anos de 1920 encontraram expressão nas mudanças introduzidas na Diretoria Geral de Instrução do Distrito Federal sob a direção de Fernando de Azevedo. À Subdiretoria Administrativa coube, além do expediente de secretaria e dos serviços de protocolo e controle da vida funcional do magistério, aperfeiçoar as modalidades de informação da Diretoria de Instrução. A criação da seção de estatística e cadastro escolar configurou, para a administração escolar, esse lugar específico de produção e gerenciamento de dados sobre a educação pública da capital. Como já se disse aqui, os principais recursos para dar à escolarização as feições de uma atividade planejada foram obtidos em função da atividade da Subdiretoria
Técnica, que então, desde a organização dos programas escolares até a edificação de novos prédios escolares, centralizou as decisões e as responsabilidades acerca do estudo e da solução dos problemas de atendimento escolar e aprendizagem. Significativamente, por meio das ações da Subdiretoria Técnica, a inspeção escolar cada vez mais se comportou como instrumento de assistência técnica. Nesse âmbito, a própria inspeção médico-escolar foi paradigmática. Entregue à chefia de um dos inspetores médico-escolares, teria a incumbência de fiscalizar, orientar e coordenar os serviços de higiene nas escolas. Conforme determinava o regulamento de ensino de 1928, era responsabilidade do inspetor médico-chefe fazer executar e fiscalizar, mas também organizar, o serviço de inspeção médica e dentaria. Cumpria principalmente à chefia do serviço médico-escolar servir, em comissão, junto à Subdiretoria Técnica como especialista.

Também politicamente a reforma administrativa da Diretoria Geral serviu para legitimar manobras de composição do poder de mando naquela repartição. Por um lado, a centralização dos serviços de secretaria no gabinete do subdiretor administrativo pareceu tornar adequada a nomeação de um funcionário de carreira na Diretoria Geral de Instrução. Tudo indica que esse aspecto não escapou a Fernando de Azevedo quando designou Frota Pessoa para o cargo. Não só coube a este chefiar um expediente que já conhecia, superintendendo e fiscalizando o protocolo, despachando e decidindo sobre a concessão de abono e justificação de faltas como também organizar os serviços de estatística e cadastro escolar na recém-criada 4 seção da Diretoria Geral. Por outro lado, em razão das atribuições estabelecidas pela regulamentação da lei do ensino de 1928 para a subdiretoria técnica da instrução, Fernando de Azevedo nomeou Vicente Licinio Cardoso, autoridade de perfil publicista reconhecida pelo magistério da capital e membro da Associação Brasileira de Educação (Tinoco, 1975). Talvez um exemplo melhor do recurso que eram as nomeações para os cargos diretivos da administração tenha sido a indicação de Jonathas Serrano para o lugar de Vicente Licinio Cardoso. A feição especializada da Subdiretoria Técnica foi reafirmada por Fernando de 
Azevedo quando nomeou o então diretor da Escola Normal da capital como o novo titular do cargo. Não só se mantinha na equipe de administração uma autoridade em educação, mas uma figura adequada para tentar implementar a reforma do ensino junto ao magistério. Fernando de Azevedo (1929) parecia mesmo entender que a realização das orientações de reforma dependia de uma rigorosa autoridade formal. Nesse sentido, outra mudança relevante no enquadramento de pessoal da repartição sob sua direção foi a criação da função de inspetor médico-chefe na subdiretoria técnica. Para desempenhá-la foi designado o inspetor médico-escolar Oscar Clark, que, de fato, como previa o regulamento de ensino, esteve empenhado em fiscalizar, orientar e coordenar os serviços de higiene nas escolas da capital. Com a chefia de Oscar Clark, em vez de uma orientação estritamente preventiva, venceu na Diretoria Geral de Instrução uma proposta de inspeção terapêutica. Os serviços de inspeção médico-escolar então cuidaram do encaminhamento e, por vezes, do tratamento das populações escolares, intensificaram o fichamento sanitário nas escolas e promoveram um curso de formação de enfermeiras escolares.

Ao deixar a direção da Instrução Pública da capital, em outubro de 1930, Fernando de Azevedo tinha realizado boa parte do que, antes, Carneiro Leão (1926, p. 198) havia proposto para dar eficiência e melhor ordem aos serviços da Diretoria Geral. Funcionavam as Subdiretorias Administrativa e Técnica, e os serviços de inspeção médica ampliaram-se de modo a propiciar tratamento às principais endemias entre a população escolar. De 1928 até 1929 as nomeações previstas no novo regulamento de ensino aumentaram muito as margens de manobra do Diretor de Instrução Pública, sobretudo servindo às estratégias de implantação da reforma educativa desenvolvidas por Fernando de Azevedo. Através de nomeações como as de Vicente Licinio Cardoso, Jonathas Serrano, Frota Pessoa e Oscar Clark, a Diretoria Geral de Instrução Pública agregou um grupo de colaboradores empenhados em promover uma plataforma de convicções renovadoras para a educação pública. Como Marta Carvalho (2004, p. 169) já demonstrou, também os laços estabelecidos entre paulistas do jornal O Estado de S. Paulo e membros da ABE que apoiaram a reforma e com ela colaboraram ampliaram os horizontes políticos e as possibilidades de implementação do programa de renovação do ensino público da capital. Fundamentalmente articuladora, a ação de Fernando de Azevedo na Diretoria Geral sustentou redes de relações pessoais e institucionais centrais à reforma que se pretendia para a educação.

Já as mudanças introduzidas na Diretoria Geral de Instrução Pública do Distrito Federal por Anísio Teixeira (1935) tornaram evidente um acentuado processo de institucionalização dos serviços educativos. A forma como Anísio desenvolveu e estendeu a capacidade de controle administrativo da educação pública entre 1933 e 1934 tanto implicou uma redefinição dos instrumentais de execução do programa de reformas do ensino carioca quanto a criação de órgãos de pesquisa e estudo. Clarice Nunes (2000, p. 237) mostrou que toda a rede de instituições que então se pôs a serviço da escolarização na cidade do Rio de Janeiro foi imaginada como "instrumento para a constituição efetiva de um sistema público de ensino”. Segundo sua avaliação, tratava-se de um esforço para enfrentar a fragmentação escolar da capital, até certo ponto entendida como reflexo da própria fragmentação social (Nunes, 2000, p. 237238). Dessa perspectiva, a organização administrativa da Diretoria de Instrução planejada e experimentada por Anísio Teixeira pode ainda ser entendida como o cerne de um projeto de melhoramento social elaborado a partir de procedimentos operacionais que exigiram um importante esforço ideologizador.

Em fins de 1933, a Diretoria Geral de Instrução Pública passou a ser denominada Departamento de Educação. O decreto n. 4.387, de 8 de setembro de 1933, instituindo o Departamento de Educação do Distrito Federal, consolidou a organização técnica e administrativa do aparelho de direção do sistema escolar. Mas não só a nova designação do órgão central da administração escolar serviu para estabelecer e legitimar os propósitos dessa repartição da prefeitura do Distrito Federal. A mudança de nomenclatura da instituição central da administração do ensino pôs em causa a articulação entre os níveis de ensino no 
sistema escolar da capital. Por essa perspectiva, o Departamento de Educação designava a ampliação dos objetivos do sistema escolar do Rio de Janeiro. Com efeito, Anísio Teixeira (1935, p. 141) autorizou o ensino secundário pelo decreto n. 3.763 , de $1^{\circ}$ de fevereiro de 1932, buscando criar os necessários vínculos da educação pós-elementar com o ensino primário e superior. Nesse sentido, também a nomenclatura foi um modo de expressar a unidade e a amplitude dos objetivos do empreendimento de reforma.

Politicamente, a trama de interesses era ainda mais cerrada. Como Carlos Eduardo Sarmento (2000, p. 33-57) e Michel Conniff (2006) deixam ver em suas pesquisas sobre a administração Pedro Ernesto, o governo da cidade se realizou pela manipulação do acesso da população aos serviços públicos e fazendo deles sua moeda essencial na negociação política. Basicamente esses autores mostram que Pedro Ernesto ampliou o leque e a abrangência dos sistemas de serviço para tentar trazer o indivíduo para o interior de uma relação de poder. Observam que, em consequência, por meio do controle de tais sistemas materializavase o principal do jogo político da cidade. Penso que também a organização do Departamento de Educação presta-se a uma análise nessa perspectiva. Não é o caso do presente estudo, que enfatiza os aspectos políticos mais circunscritos à reestruturação dos serviços administrativos da educação pública.

Em todo caso, o modelo organizacional sob o qual funcionou o Departamento de Educação havia tanto comprometido o poder público com o "controle eficiente" dos processos de escolarização na capital quanto criado a possibilidade de estruturar um campo de especialização profissional em meio ao jogo político da cidade. Assim, as mudanças que Anísio Teixeira impôs nos padrões de controle escolar da demanda por educação mostraram ser mais que o resultado de uma estratégia para reconstituir o funcionamento do sistema público de educação. O empreendimento de reforma do órgão central da administração do ensino contribuiu parcialmente para a redistribuição das responsabilidades de controle, assistência técnica e experimentação, intensificando a supervisão e a regulamentação da educação pública. Contudo, as finalidades de articulação dos níveis de ensino e das instituições para a sua administração não se impuseram sem conflitos. Apesar de Anísio ter contemporizado com a legislação federal, ele divergiu das exigências da União na sua ação, das propostas dos grupos católicos e esquerdistas no seu programa de reformas e da rotina de trabalho das próprias escolas em funcionamento na implantação das suas iniciativas. As reações ao que se propunha como estratégia de organização técnica e especializada da escola pública indicavam o caráter polêmico da gestão de Anísio Teixeira. Nesse sentido, parece-me preferível pensar aqui a reforma do Departamento de Educação da capital federal entre 1933 e 1934 a partir do seu ajustamento à diversidade de ações dos vários grupos de interesse envolvidos a discutir a condução política do processo de reforma (Nunes, 2000), o alcance das suas realizações (Garibello, 1977; Teixeira, 1985) ou o ideário por meio do qual se expressaram as competências do seu discurso (Gandini, 1980; Nunes, 2001).

\section{As estratégias de gabinete}

Anísio Teixeira (1935, p. 103) tinha clareza quanto ao método por meio do qual procurava resolver os problemas escolares do Rio de Janeiro:

\footnotetext{
O administrador sincero perdeu, desde que examinou um pouco mais profundamente a situação, a ilusão dos planos integrais e perfeitos, desenvolvidos a golpes de lógica e de doutrina.

A realidade contraditória, desigual e incerta obrigou-o a planos desiguais para a conquista de uma progressiva coerência de todo o sistema.

Esta, a distinção mais assinalável na atual administração do ensino no Distrito Federal. O método por que estamos procurando resolver o problema escolar do Rio de Janeiro é o da experimentação gradual das soluções e o da obediência rigorosa às condições locais.
}

A passagem é representativa da transigência de Anísio diante da situação de desigualdade de condições materiais e pessoais do sistema escolar carioca. 
Como também fazem entender os testemunhos de Paschoal Lemme (1988, p. 151) e Juracy Silveira (1960), a ação do Departamento de Educação entre 1933 e 1935 tanto foi flexível quanto obedeceu às condições locais de realização das iniciativas de reforma. Por um lado, o testemunho de Juracy Silveira (1960) aponta os ajustes progressivos das regulamentações e das orientações do trabalho educativo. Por outro lado, o depoimento de Paschoal Lemme (1988, p. 151) é indicativo do quanto se consideraram as manifestações de ambições e interesses pessoais para que a consecução dos objetivos centrais da reforma não fosse prejudicada. Com efeito, as modificações dos decretos, a republicação de instruções e a política de pessoal observadas durante a reforma do ensino no Distrito Federal advertem sobre a existência de estratégias de composição e organização do poder de decisão no Departamento de Educação pouco aparentes, mas decisivas para a implantação da nova política escolar.

Como Carneiro Leão e Fernando de Azevedo, Anísio Teixeira também se valeu das designações e da regulamentação para produzir mudanças no funcionamento dos serviços educativos da capital. Em parte, tratou de criar alianças e conseguir apoio político. Nesse âmbito, a reorganização que Anísio conseguiu realizar na Diretoria Geral de Instrução Pública resultou da sua capacidade de regular o trabalho de diversas divisões especializadas. Entrementes, a expansão dos serviços de administração do sistema educativo da capital absorveu parte do grupo que trabalhou na reforma do ensino em 1928, explicitando a solidariedade de Anísio com a obra de Fernando de Azevedo. Como percebeu Diana Vidal (1998, p. 76), a indicação de Anísio para dirigir a instrução carioca respondia às reivindicações da $\mathrm{ABE}$, especialmente na tentativa de recuperar a imagem de alguns educadores hostilizados com as mudanças políticas ocasionadas pela Revolução de 1930. Anísio Teixeira assumiu sem dificuldades um discurso de continuidade com as gestões de Fernando de Azevedo e de Carneiro Leão. Preocupadas em renovar a escola brasileira, de fato defendiam uma concepção de ensino centrada na criança e no interesse infantil. No entanto, como fazem ver os estudos de Vidal (1998, 2001), a fala da continuidade no fazer administrativo assumiu caráter de diferença. Essas pesquisas advertem acerca da singularidade das ações reformistas de Azevedo e Anísio.

Na tentativa de desembaraçar as falas de Anísio e Fernando, Vidal (1998, p. 76) destaca as suas diferenças de acepção quanto ao ensino laboratorial, às diretrizes fixadas para o ensino primário, ao trabalho de organização administrativa e à formação docente. Tendo em vista as singularidades da ação reformista de um e outro, compreende a maneira distinta de perceberem a formação para o magistério e a função da escola pública. Fernando de Azevedo preocupou-se em estruturar a Escola Normal, prevendo-lhe anexos em quantidade suficiente para a prática em laboratórios, escolas de aplicação e gabinetes para a pesquisa aplicada, procurando harmonizar cultura utilitária e estudos desinteressados. Para Anísio Teixeira, formar professores era desenvolver-lhes a atitude científica, "munindo-os de um saber técnico específico, de um instrumental de análise capaz de subsidiá-los na resolução de problemas práticos” (Vidal, 1998, p. 91). Segundo Vidal (1998, p. 93), a constituição da Escola de Professores do Instituto de Educação foi o exemplo prático de observância desse ideal. A respeito das funções da escola pública Azevedo e Teixeira emitiram enunciados comuns; no entanto, diferiram quanto aos procedimentos. Em ambos, a sociedade, percebida como em permanente mudança, exigia uma escola capaz de efetuar a educação progressiva do indivíduo aos novos ritmos da civilização. Contudo, como bem compreendeu Vidal (1998, p. 94), enquanto "para Fernando a difusão de ideias transformaria a prática, Anísio, diferentemente, percebia a mudança não como uma simples conquista da propagação de um ideário, mas como resposta a uma ação prática”.

Noutra perspectiva, os sucessivos decretos de reforma configuraram um campo de operações por meio do qual Anísio Teixeira buscou estabelecer, no embate das lutas sociais do período, novos espaços de atuação do educador e seu valor social. Conforme mostrou E. P. Thompson (1987, p. 358), enquanto regras e procedimentos formais e como ideologia, a legislação não pode 
ser proveitosamente analisada nos termos metafóricos de uma superestrutura distinta de uma infraestrutura. Fundamentalmente, a análise do caráter político da intervenção legal baseia-se na compreensão de que também a lei, em sua dinâmica e contradições, objetiva a própria dinâmica das relações sociais. Assim, um segundo aspecto das lutas e tensões em torno do controle da educação pode ser visto nas relações estabelecidas entre a própria lei e as estratégias de intervenção de diferentes grupos no campo educativo. Nesse sentido, as pesquisas de Nunes (1996, p. 200; 2000, p. 392-394) exploram as resistências dos grupos diretamente atingidos pelo trabalho de produção da legislação escolar realizado no Departamento de Educação. Desde as queixas divulgadas por comunicado à imprensa até as pressões pessoais sobre Anísio por companheiros de trabalho, foram vários os casos registrados de violação da regra prescrita, "mediante uma atitude de recusa a acatá-la, descaso ou distorção na sua aplicação” (Nunes, 2000, p. 393).

Acerca do que dizem os estudos de Nunes (2000, p. 392) sobre as tensões entre os imperativos legais e as circunstâncias políticas de sua implantação, percebe-se que por traz da experimentação gradual das soluções e da obediência rigorosa às condições locais havia cerrada disputa de poder, a fim de definir "um conjunto de soluções jurídicas para problemas postos pelo contexto pedagógico”. Também Carneiro Leão e Fernando de Azevedo sofreram resistência importante. Carneiro Leão nem mesmo viu enviada ao Conselho Municipal sua proposta de reforma da instrução. Alaor Prata, então prefeito da cidade, demoveu Carneiro Leão (1926, p. 201) da ideia de pôr a iniciativa de reforma na dependência da audiência do Conselho Municipal. Já Fernando de Azevedo o fez, com o completo apoio da prefeitura de Antônio Prado Júnior. Segundo o próprio Azevedo (1929, p. 38), tratava-se de um projeto "com vigoroso espírito de síntese, em que se acentuam as linhas diretrizes, inspiradoras e predominantes, bastante firmes para darem um caráter de harmonia e homogeneidade ao conjunto de todas as instituições escolares”. A aprovação do decreto de reforma, após meses de discussão no Conselho Mu- nicipal, foi uma vitória política de impacto, mas não totalmente livre de desgastes. Ao estudar a tramitação do projeto de reforma, Nelson Piletti (1994, p. 114) mostrou que foram justamente os situacionistas que fizeram oposição, na tentativa de obter vantagens. A aprovação foi obra de articulação dos oposicionistas e independentes, que, em fins de 1927, adotaram a estratégia de obstruir a votação do orçamento de 1928. Em 26 de dezembro, passaram a lei de reforma e o orçamento. A insatisfação de Campos Medeiros (1928) é exemplar da perspectiva pela qual se criticou a sanção das medidas previstas na reforma do ensino:

Que valeram as considerações judiciosas do emérito prof. Alberico de Moraes? Que valeram as objeções feitas por Brício Filho, o eminente e erudito prof. da Escola Normal? Que valeram os artigos de Alberto Moreira, brilhantíssimo, no Jornal do Brasil?

Não valeram quase nada...

Valeram muito, é certo, para os que estavam na plateia, observando sem interesses de emprego. Mas, para os que estavam no palco, ansiosos pela reforma, para estes todos os argumentos eram interpretados como manifestações de má vontade.

E a reforma passou. Passou amputada. - Passou sem um grande número de extravagâncias, das maiores. Ficou, porém, muita coisa inútil e dispendiosa, para as quais não houve argumento capaz de demover nem os interessados administrativos nem os legisladores.

Chegou-se, pois, no Brasil, a este resultado: a inutilidade do debate, mesmo nas questões técnicas. O interesse pessoal fala mais alto que o raciocínio!

Ora, se antes da reforma votada e promulgada, de nada valeram objeções - de que valerão agora, que tudo está consumado? (p. 7)

Contra argumentos como esses de Campos Medeiros, Fernando de Azevedo e alguns dos seus principais colaboradores na Diretoria de Instrução e na imprensa, insistiram que a reforma era obra integral, atual e previdente, de longo prazo. Por diversos meios, procurou-se consolidar a ideia de que a nova legislação do ensino era um plano harmônico e articulado de remodelação 
educativa. As entrevistas de Azevedo (1929) sobre a reforma educativa que então ele buscava implantar na capital apontam para uma estratégia de legitimação sobretudo atenta às formas de garantia e controle da legalidade das ações sobre a educação pública. A preocupação com o corpo de doutrina da lei de ensino foi uma característica constitutiva dessas entrevistas. Tanto há o esforço de mostrar que uma nova concepção pedagógica foi integrada à legislação quanto o empenho de explicitar o modo como se pensou a execução das iniciativas previstas em lei (Azevedo, 1929, p. 86). Antes de qualquer outra coisa, o ordenamento jurídico pretendido pela lei de ensino de 1928 para Azevedo (1929, p. 129-140) constituiu fonte e indício de fundamentação e consistência da reforma educativa. De certa forma, assegurar a legitimidade da lei de ensino foi fundamental para formalizar novas práticas de funcionamento das escolas, garantindo a execução não só de iniciativas de ordenação e controle, mas também de inovação da estrutura educativa da capital. Nesse sentido, ao contrário de Anísio, que conduziu um trabalho contínuo de regulamentação do ensino, Azevedo operou de acordo com um programa de ação duradouro, produzido de maneira integral e homogênea.

No entanto, operações de outro tipo acentuaram as diferenças entre os fazeres administrativos de Carneiro Leão, Fernando de Azevedo e Anísio Teixeira. Mediante o repertório de práticas em uso, cabe advertir que as diferenças das quais vou tratar em seguida são apenas de ênfase. As distinções que se pretende realizar entre as ações de Carneiro Leão, Fernando de Azevedo e Anísio Teixeira na Diretoria Geral de Instrução Pública do Distrito Federal não devem ser entendidas como uma análise da originalidade de cada uma das gestões. Tratase apenas de enfocar as principais direções assumidas por Carneiro Leão, Fernando de Azevedo e Anísio Teixeira na gestão da Diretoria de Instrução, sem com isso negar a continuidade das demais práticas no fazer cotidiano da administração de cada um deles.

Carneiro Leão organizou sua ação administrativa sobretudo através das comissões de trabalho. Por meio do trabalho comissionado realizaram-se, entre 1923 e 1926, tanto as experimentações com os testes quanto os cursos de formação em desenho e modelagem e em educação física e os serviços de registro e estatística da Diretoria Geral de Instrução. Nesse modo de conduzir os trabalhos de inovação, Carneiro Leão não só conferiu autoridade de especialistas a grupos de professores da Escola Normal, das escolas profissionais ou mesmo das escolas primárias como também parece ter se aproveitado do reconhecimento que parte desses professores já tinha junto ao magistério da capital. De certa forma, foi assim que o diretor da Instrução Pública da cidade à época criou as redes de "solidariedade" profissional necessárias para assegurar alguma legitimidade às inovações pretendidas. Dessa perspectiva, as práticas por meio das quais Carneiro Leão dirigiu a Instrução Pública ultrapassam a idealização que reflexões como as de Zentgraf (1994) e Sandra Mendonça (1997) sublinham quando tratam desse período administrativo.

Fernando de Azevedo reuniu condições para centralizar decisões de infraestrutura e recursos materiais em seu gabinete. No quadriênio administrativo de Azevedo, os editais para construção de escolas foram elaborados na própria Diretoria de Instrução. Do mesmo modo, a Instrução Pública passou a ter um almoxarifado privativo. Os serviços de saúde escolar também ficaram centralizados numa chefia subordinada à Subdiretoria Técnica. Noutro âmbito, a ênfase na difusão das ideias que Diana Vidal (1994, p. 95) identifica na administração de Fernando de Azevedo pode ser também vista nas práticas de comunicação da Diretoria de Instrução. As relações de Azevedo com os jornalistas da capital - ele, que trabalhou no jornalismo paulista - caracterizaram-se pela publicação regular de comunicados na imprensa em resposta às críticas ou informando o público das decisões administrativas e resultaram em larga repercussão social das ideias da reforma do ensino. De fato, a capacidade de repercussão que teve a reforma do ensino desde 1927 é um elemento de importância para a compreensão do fazer administrativo de Azevedo na Diretoria de Instrução.

A obra administrativa de Anísio Teixeira pode ser vista com igual riqueza da perspectiva da instituciona- 
lização dos serviços educacionais. A transformação da Diretoria Geral de Instrução Pública em Departamento de Educação no ano de 1933 apresentou-se como a expressão mais lógica de uma estrutura em que os papéis e as tarefas eram bastante definidas:

Indispensável, entretanto, se torna acentuar o cuidado que se pôs em dotá-la de organismos diferenciados para as diversas funções, ao mesmo tempo que se conseguiu uma rigorosa unidade de linhas de ação. Para isso, creio que sobreleva, dentre todas as medidas, a distinção que se fez, nítida e expressa, entre a atuação executiva, ou "linhas de comando" e a assistência técnica, ou "linhas consultivas".

[...]

Numa elaboração mais complexa de planos, a distinção se faz até nos tipos de autoridades que velam pelo cumprimento do mister de educar - há o que provê os objetivos e as condições de sua realização e o que assiste e auxilia a execução. Na organização proposta, tais diferenciações se tornam, muito precisas; o professor executa, o orientador assiste e instrui e o diretor e superintendente delimitam os planos e dispõem das melhores condições para o êxito final do mestre. (Teixeira, 1935, p. 66)

Anísio Teixeira (1935, p. 68) definiu os órgãos de atuação do Departamento de Educação tendo em vista as funções e os planos de trabalho de cada um deles. Procurou expressar uma forma organizativa desdobrada em vários órgãos de estudo, coordenação e elaboração de planos, como ainda em aparelhos de fiscalização, orientação e assistência. Anísio e seus colaboradores conseguiram pôr em funcionamento uma estrutura administrativa apoiada sobre a fisionomia técnica e especializada que a direção geral da educação pretendia ter.

Em relação às manobras orçamentárias da instrução pública, Carneiro Leão, Fernando de Azevedo e Anísio Teixeira também constituíram estratégias bastante específicas. Carneiro Leão, muito em função de perceber a redução dos recursos financeiros da prefeitura destinados ao ensino, disse não ter contado com dotação orçamentária sequer para cobrir os gastos correntes. Em relatório, requisitou a atenção dos homens de governo para o fato de a educação ser um investimento para o futuro, a possibilidade de o povo de se preparar "para a luta pela vida” (Carneiro Leão, 1926, p. 214). Fundamentalmente, ele (1926, p. 19) defendeu o custeio da educação pública por meio de um imposto escolar sobre a renda, propondo então a criação de rubricas de obrigações e empréstimos para a obtenção de recursos federais ao ensino municipal. Fernando de Azevedo, por sua vez, insistiu na organização de iniciativas para a obtenção de recursos privados. O estímulo que Carneiro Leão havia dado ao desenvolvimento de caixas escolares, das ligas de bondade e até mesmo de um conselho de assistência escolar foi previsto na lei de reforma que Azevedo conseguiu ver aprovada junto ao Conselho Municipal. Nesse âmbito, entre 1927 e 1930 Azevedo incentivou a criação de caixas escolares e a autogeração de rendimentos das escolas, principalmente as de caráter profissional. Outra prática que ele apontou na prática administrativa da Diretoria de Instrução a partir de 1927 foi a busca de convênios com entidades beneméritas, de assistência e tratamento de saúde. Sem perder nada dessas experiências, Anísio Teixeira operou, por meio de decretos-lei, a criação de um fundo escolar, vários redirecionamentos de verbas mediante estornos de uma dotação orçamentária para outra e aberturas regulares de créditos especiais para as construções e remodelações de equipamentos educativos.

Também nesse âmbito se pode observar Anísio agindo segundo circunstâncias especificadas pela necessidade e Fernando de Azevedo de acordo com princípios de mais longo alcance. Não é difícil ver o quanto Carneiro Leão percebeu das necessidades de financiamento público da educação quando se estudam as medidas tomadas em seguida por Azevedo e Anísio. Ainda que, por um lado, Azevedo tenha focado a captação de recursos de particulares beneméritos e os convênios e, por outro, Anísio tenha buscado definir melhores canais de financiamento público, ambos procuraram incrementar instituições capazes de auxiliar os custos da distribuição de merenda, de assistência social e de aperfeiçoamento e valorização do magistério. Cumpre notar ainda que a maior ênfase 
de Azevedo na organização de caixas escolares visando a captação de recursos advindas de particulares não deixou de contar com substanciais aportes de recursos públicos para a construção de edifícios escolares. Do mesmo modo, as manobras orçamentárias de Anísio Teixeira não dispensaram os dispositivos de lei que regulamentavam as caixas econômicas e escolares desde a reforma do ensino de 1928.

Outra dimensão das estratégias administrativas que parece oportuno destacar aqui diz respeito à consolidação dos dados estatísticos da Diretoria Geral de Instrução Pública à época. Do mesmo modo que as estratégias administrativas e as manobras orçamentárias, as estatísticas publicadas entre 1922 e 1935, quando comparadas, apresentam especificidades. Tanto nas categorias mensuradas quanto na inteligibilidade que conferiam à realidade, o registro estatístico no período foi produzido segundo circunstâncias objetivas de construção da eficiência administrativa de cada gestão.

Nesse sentido, Carneiro Leão (1926) organizou e publicou estatísticas sobre o rendimento escolar e o alcance dos serviços médico-escolares. Por um lado, pôde mostrar que as crianças não só estavam se mantendo por mais tempo na escola como o número de promoções crescia nas escolas do Distrito Federal (Carneiro Leão, 1926, p. 11). Por outro, Carneiro Leão (1926, p. 6061) deu a conhecer os bons resultados nos índices de aumento de peso e altura das crianças produzidos nas escolas com distribuição regular de alimentos.

Igualmente, apenas se encontram publicados no quadriênio seguinte os índices relativos ao recenseamento escolar e aos serviços médico-escolares. De fato, os números da inspeção médico-escolar tiveram aumento expressivo entre 1927 e 1930, ultrapassando em muito os resultados apresentados por Carneiro Leão. No caso do recenseamento, os números serviram para iniciar uma política de edificações escolares, justificando-se a construção de escolas nas áreas com maior número de crianças em idade escolar. Embora não tenha havido menção ao recenseamento no efetivo momento de edificação dos prédios, o papel desses índices no debate público gerado em torno da reforma do ensino público no Distrito Federal não foi desprezado.
Cecília Hanna Mate (2002, p. 68) mostra, inclusive, que a prática do censo permitia perceber "que novas técnicas surgiam para uma série de melhorias sociais”.

Dessa perspectiva, não é por acaso que a publicação, entre 1932 e 1935, das estatísticas sobre números de vagas e de frequência nas escolas da capital indicativos de rendimento escolar e expansão dos serviços médicoescolares indique o aumento de matrícula, a melhoria dos índices de rendimento escolar e o aumento da capacidade de atendimento escolar no período. E, de fato, o Departamento de Educação conseguiu elevar todos os registros estatísticos, se comparados aos períodos administrativos anteriores, principalmente a partir da organização em departamento da Diretoria de Instrução. Anísio Teixeira (1935) apresentou progressos em áreas de intervenção social já identificadas nas reformas do ensino público promovidas por Azevedo e Carneiro Leão.

Os avanços que Carneiro Leão (1926, p. 10) apresentou nos índices de rendimento escolar entre 1923 e 1926 proveram um princípio organizador para a enunciação do problema enfrentado pela reforma do ensino. Parte da obra Ensino na capital do Brasil definiu a questão do aproveitamento escolar em termos de medidas estatísticas, servindo para argumentar que a administração estava "conseguindo que o filho do povo se vá mantendo por um tempo mais longo na escola, para elevar a média geral da cultura da massa popular" (Carneiro Leão, 1926, p. 12). Do mesmo modo, a partir de 1928 o melhoramento dos números da inspeção médico-escolar teve ampla cobertura estatística, servindo para moldar, segundo expressão de Popkewitz e Lindblad (2001, p. 117), uma maneira de ver as possibilidades de ação e de inovação dos serviços educacionais. Os resumos dos serviços de inspeção médico-escolar foram mensalmente publicados na imprensa diária e trimestralmente no Boletim de Educação Pública (1930, p. 136), realçando a importância que assumiu na obra de reforma do ensino o "problema complexo da higiene física do aluno e da higiene escolar”. Assim, também os resultados que Anísio Teixeira obteve nas percentagens de matrícula e frequência e de aproveitamento davam a ver dados que convidavam a comparações entre essas categorias ao longo do tempo. E a linguagem que atra- 
vessou os relatórios do diretor de educação em 1934 marcou diferenças e gerou normas que qualificavam a reforma da educação pública na capital empreendida desde 1931. Fundamentalmente, o que Carneiro Leão, Fernando de Azevedo e Anísio Teixeira distinguiram e enumeraram em suas administrações lhes permitiu estabelecer bases para enunciarem os progressos.

Como se procurou mostrar aqui, entre 1922 e 1935 o advento reformista na educação pública da cidade do Rio de Janeiro foi unitário apenas na aparência. A regulamentação dos serviços educativos, a eficiência administrativa e a quantificação dos resultados em estatísticas constituíram apenas uma moldura dentro da qual é possível observar o desenho de diferentes estratégias. Os traços característicos das administrações Carneiro Leão, Fernando de Azevedo e Anísio Teixeira e suas interligações parecem singulares em muitos aspectos. Em relação ao problema específico do controle administrativo dos serviços educativos da capital, esta análise ficou circunscrita ao que se poderia considerar como estratégias de gabinete. Essencialmente, ela abordou a organização que Carneiro Leão (entre 1922 e 1926), Fernando de Azevedo (de 1927 a 1930) e Anísio Teixeira (a partir de 1931 até 1935) deram à Diretoria de Instrução do Distrito Federal, o modo como se delinearam suas atividades. Dessa perspectiva, o principal foco deste estudo recaiu sobre a gestão da reforma do ensino, a política de pessoal e de obtenção de recursos e o controle de resultados. Em muitos aspectos, no entanto, o que me parece ser relevante aventar como conclusão de pesquisa é mais a distinção das diferentes estratégias organizacionais desenvolvidas à época do que propriamente os resultados obtidos pelas reformas educativas dos anos de 1920 e 1930 na capital do país.

O propósito de também perceber as decisões de gabinete como ações de governo permitiu questionar diferentes estratégias de mando. Não obstante se poder dizer que herdaram e repetiram procedimentos de organização da educação pública, Carneiro Leão, Fernando de Azevedo e Anísio Teixeira arranjaram-se com eles, inventando e improvisando com indiscutível originalidade. Nesse sentido, o estudo de decisões e atos administrativos desse período intensifica as distinções entre as suas práticas e fazeres. Como a organização do mando na Diretoria de Instrução envolveu situações particulares, pareceu-me útil tratar aqui das estratégias de empoderamento que cada novo gabinete adotou entre 1922 e 1935 como forma de compreender a relevância das ações de gestão em cujo interior os esforços de reforma do ensino se tornavam inteligíveis.

\section{Referências bibliográficas}

AZEVEDO, Fernando de. A reforma do ensino no Districto Federal: discursos e entrevistas. São Paulo: Melhoramentos, 1929.

CARNEIRO LEÃO, Antonio. O ensino na capital do Brasil. Rio de Janeiro: Typ. do Jornal do Commercio, 1926.

CARVALHO, Marta Maria Chagas de. O Manifesto e a Liga Internacional pela Educação Nova. In: XAVIER, Maria do Carmo (Org.). Manifesto dos pioneiros da educação: um legado educacional em debate. Rio de Janeiro: Editora FGV, 2004. p. 147-182.

CONNIFF, Michel. Política urbana no Brasil: a ascensão do populismo, 1925-1945. Rio de Janeiro: Relume Dumará, 2006.

DISTRITO FEDERAL. Decreto n. 3.281, de 23 de janeiro de 1928. Reforma do Ensino no Distrito Federal. In: DISTRITO FEDERAL. Lei e regulamento do ensino. Rio de Janeiro: Oficinas Gráficas do Jornal do Brasil, 1929. p. 7-109.

. Decreto n. 3.763, de $1^{\circ}$ de fevereiro de 1932. Modifica algumas disposições do Decreto n. 3.281, de 23 de janeiro de 1928. In: PAGANI, Ivo; VELLOSO, Guilherme Paranhos; DIAS, Alexandre. Coleção de Leis Municipais Vigentes - 1932 a 1935. v. 5. Rio de Janeiro: Oficinas Gráficas do Jornal do Brasil, 1937. p. 359-364. . Decreto n. 4.387, de 8 de setembro de 1933. Consolida a organização técnica e administrativa do aparelho de direção do sistema educacional, instituindo o Departamento de Educação do Distrito Federal. In: PAGANI, Ivo; VELLOSO, Guilherme Paranhos; DIAS, Alexandre. Coleção de Leis Municipais Vigentes-1932 a 1935. v. 5. Rio de Janeiro: Oficinas Gráficas do Jornal do Brasil, 1937. p. 427-436.

GANDINI, Raquel Pereira Chainho. Tecnocracia, capitalismo e educação em Anísio Teixeira (1930-1935). Rio de Janeiro: Civilização Brasileira, 1980.

GARIBELLO, Wanda Pompeu. Anísio Teixeira: análise e sistematização de sua obra. São Paulo: Atlas, 1977.

HANNA MATE, Cecília. Tempos modernos na escola: os anos 30 e a racionalização da educação brasileira. Bauru: EDUSC; Brasília: INEP, 2002. 
LEMME, Paschoal. Memórias. v. 2. São Paulo: Cortez; Brasília: INEP, 1988.

MEDEIROS, Campos de. Ensino Municipal. Reforma, Rio de Janeiro, p. 7-8, 29 fev. 1928.

MENDONÇA, Sandra Cabral. Carneiro Leão: sonho e frustrações na Diretoria de Instrução Pública do Distrito Federal (1922-1926). Dissertação (Mestrado em Educação) - Pontifícia Universidade Católica do Rio de Janeiro, Rio de Janeiro, 1997.

NAGLE, Jorge. Educação e sociedade na Primeira República.

São Paulo: EPU; Rio de Janeiro: Fundação Nacional do Material Escolar, 1974.

NUNES, Clarice. Cultura escolar, modernidade pedagógica e política educacional no espaço urbano carioca. In: HERSHMANN, Micael (Org.). Missionários do progresso. Rio de Janeiro: Diadorim, 1996. p. 115-224.

. Anísio Teixeira: a poesia da ação. Bragança Paulista: EDUSF, 2000.

NUNES, João Roberto Oliveira. A administração Pedro Ernesto e a questão educacional. Rio de Janeiro: EDUERJ, 2001.

PILETTI, Nelson. A reforma da educação pública no Distrito Federal 1927-1930: algumas considerações críticas. Revista da Faculdade de Educação, v. 20, n. 1 e 2, p. 107-131, jan./dez. 1994. POPKEWITZ, Thomas; LINDBLAD, Sverker. A estatística educacional como um sistema de razão: relação entre governo da educação e inclusão e exclusão social. Educação e Sociedade, ano XXII, n. 75, p. 111-148, ago. 2001.

SARMENTO, Carlos Eduardo. A arquitetura do impossível - a estruturação do Partido Autonomista do Distrito Federal e o debate autonomista nos anos 1930. In: FERREIRA, Marieta de Moraes (Coord.). Rio de Janeiro: uma cidade na história. Rio de Janeiro: Editora FGV, 2000. p. 33-57.

SERVIÇO médico e dentário escolar. Boletim da Educação Pública, ano I, n. 1, p. 136-138, jan./mar. 1930.

SILVEIRA, Juracy. Alguns aspectos da reforma Anísio Teixeira, no Rio de Janeiro. In: ABREU, Jayme (Org.). Anísio Teixeira: pensamento e ação. Rio de Janeiro: Civilização Brasileira, 1960. p. 191-209.

TEIXEIRA, Anísio. Educação publica: administração e desenvolvimento. Relatório do Director Geral do Departamento de Educação do Districto Federal - dezembro de 1934. Rio de Janeiro: Oficina Gráfica do Departamento de Educação, 1935.

TEIXEIRA, Mirene Mota Santos. O significado pedagógico da obra de Anísio Teixeira. São Paulo: Edições Loyola, São Paulo, 1985.
THOMPSON, Edward Palmer. Senhores e caçadores: a origem da lei negra. Rio de Janeiro: Paz e Terra, 1987.

TINOCO, Marta Maria Chagas de Carvalho. Vicente Licinio Cardoso: pensamento e ação educacional. Dissertação (Mestrado em Educação) - Faculdade de Educação, Universidade de São Paulo, São Paulo, 1975

VIDAL, Diana. Nacionalismo e tradição na prática discursiva de Fernando de Azevedo. Revista do Instituto de Estudos Brasileiros, n. 37, p. 35-52, 1994.

. Desembaraçando algumas falas: aspectos das reformas Fernando de Azevedo e Anísio Teixeira no Distrito Federal (1927-1935). Cadernos de História e Filosofia da Educação, São Paulo: Faculdade de Educação da USP, v. 2, n. 4, p. 75-98, 1998. O exercício disciplinado do olhar: livros, leituras e práticas de formação docente no Instituto de Educação do Distrito Federal (1932-1937). Bragança Paulista: EDUSF, 2001. (Coleção Historiografia.)

ZENTGRAF, Maria Christina Santos Rocha. Projetos pedagógicos na Primeira República Brasileira: a contribuição de Antônio Carneiro Leão. Tese (Doutorado em Educação) - Faculdade de Educação, Universidade Federal do Rio de Janeiro, Rio de Janeiro, 1994.

ANDRÉ LUIZ PAULILO, doutor em educação pela Universidade de São Paulo (USP), é professor da Universidade Municipal de São Caetano do Sul e pesquisador do Núcleo Interdisciplinar de Estudos e Pesquisas em História da Educação da USP (NIEPHE-USP). Publicações recentes: A reforma de Fernando de Azevedo em artigos de imprensa e sua ação política na Diretoria de Instrução Pública do Distrito Federal (1927-1930) (In: VIDAL, Diana (Org.). Educação e reforma: o Rio de Janeiro nos anos 1920-1930. Belo Horizonte: Argvmentvm; São Paulo: NIEPHE, 2008. p. 45-58); O avesso da norma: indolentes, vadios, imprudentes e outros tipos escolares (Revista Brasileira de História da Educação, n. 15, p. 117-136, set./dez. 2007); Política educacional e renovação escolar na capital da Velha República (Estudos de História, v. 13, n. 1, p. 43-78, 2006). Pesquisa em andamento: “A estratégia como invenção: as políticas públicas de educação na cidade do Rio de Janeiro entre 1922 e 1935”. E-mail: paulilo@uscs.edu.br

Recebido em junho de 2008 Aprovado em julho de 2009 